\title{
Reseña sobre Ciudadanias conectadas. Sociedades en conflicto. Investigaciones sobre medios de comunicación, redes sociales y opinión pública, de Carlos Andrés Charry Joya*
}

Milciades Vizcaino $G .^{\text {a }}$

Universidad Cooperativa de Colombia, Colombia milci.vizcaino@gmail.com

ORCID: https://orcid.org/0000-0002-6468-4064

DOI: https://doi.org/10.11144/Javeriana.uh88.rccs

Recibido: 15 Octubre 2019

Aceptado: 28 Noviembre 2019

Publicado: 20 Diciembre 2019

La publicación del libro por la Universidad del Rosario es un avance en la investigación sobre conflictos sociales, medios de comunicación y opinión pública. Un aspecto relevante es que los siete capítulos fueron escritos por diferentes autores desde enfoques teóricos, metodológicos y disciplinares distintos. Un punto de partida es la afirmación de Manuel Castells en el sentido de que "la batalla más importante que hoy se libra en la sociedad es la batalla por la opinión pública" por cuanto las personas dirigen sus vidas según las normas y los valores que circulan en los medios, sobre todo aquellos que usan las tecnologías de mayor capacidad de difusión y de reproducción reconocidos, a su vez, como los medios más apropiados para estar informado. Los medios de comunicación camuflan su poder en el marco (frame), en la agenda informativa (agenda setting) y en la realidad construida (priming). Cuando se estudia la movilización juvenil, las TIC y las esferas públicas, se introduce la historia y los desarrollos de la opinión pública desde Habermas hasta Castells, pasando por Tilly, Beinin y Vairel, y Morozov, quienes discuten el poder de los medios en relación con los movimientos sociales en la organización política y socioeconómica para la formación de los Estados nación. En la dinámica se ven articulados los jóvenes con tecnologías multitareas, multiculturales, multilingües, multigéneros y multitecnológicas. La penetración de Facebook, Twitter o WhatsApp en Colombia es inédita en la historia reciente, sobre todo en las nuevas generaciones. Igual fenómeno ocurre en todos los países del mundo con variaciones tecnológicas, sociales y culturales. Por tanto, los movimientos sociales están impregnados por los contenidos de los medios de comunicación, la información, y las opiniones públicas y las tecnologías que anuncian que nos encontramos en el camino de la cuarta revolución tecnológica en el mundo.

Los movimientos sociales, sobre todo aquellos que son impulsados por la fuerza de la guerra, han promovido la conformación de ciudadanías comunicativas que se reconocen en su identidad alrededor de la pérdida producida de manera violenta y de la cual no se sobreponen por las profundas huellas producidas. Sin embargo, las víctimas, como las mujeres de Medellín o las de Soacha, tienen una reserva de fuerza para construir organizaciones que delatan a los victimarios y los colocan ante la justicia de Colombia. Es un fenómeno similar a las Madres de la Plaza de Mayo en Argentina, el Colectivo de las Mujeres de Negro en Serbia, el Grupo de Defensoras en Centroamérica, el grupo de Nuestras Hijas de Regreso a Casa en México, el Centro Femenino para Superar el Trauma en Sudáfrica, o las Madres del Sábado en Turquía. Se ha esbozado un sistema de valores a escala global fundamentado en la memoria social, el reconocimiento y la solidaridad, a través de los cuales hacen el tránsito de víctimas a ciudadanos con valores universales en una esfera social global. La cultura de la paz ha de involucrar a estas ciudadanías provenientes del horror del conflicto armado en calidad de víctimas y ahora de ciudadanos universales.

La opinión pública, especialmente urbana en un $75 \%$, fue informada de las negociaciones del presidente Juan Manuel Santos con las FARC en la búsqueda de la paz, primero a cuenta gotas y luego en un crescendo

Notas de autor

a Autor de correspondencia. Correo electrónico: milci.vizcaino@gmail.com 
vertiginoso que incidió en la polarización social y política de refrendación ciudadana, y luego en el control social mediador entre los individuos y las instituciones. Para los estudiosos de los medios masivos, se ha evidenciado el poder que tienen estos en la política del Estado en las conexiones entre interacción, emoción, cognición y comportamiento político. El Internet ha modificado la comunicación, la información y la interacción entre los ciudadanos y la legitimidad de las instituciones públicas que inciden en la creación de los marcos cognitivos de la memoria social culturalmente construida. La oleada de información a través de los medios en asocio con las redes sociales acerca de la paz con las FARC fue sustituida luego por temas de la corrupción, la violación de menores, el feminicidio, la protesta social y la crisis de Venezuela. Estos hechos borraron la primera atención a las negociaciones de paz.

Otro trabajo se detuvo en el ethos visual y en el rito de institucionalización de la desmovilización de las FARC. A pesar del feliz término de la negociación, su legitimación fue cuestionada por un sector amplio de la población que se manifestó en el plebiscito del 2 de octubre. Pese a ello, los reintegrados se desplazaron a las sedes veredales acordadas, lo cual fue entendido como un rito de institución, según Pierre Bourdieu, y como un rito de paso hacia la paz y la civilidad representadas en el orden moral de la sociedad.

El tema de los movimientos animalistas en los medios escritos de mayor circulación en Colombia demuestra que los nuevos movimientos sociales ya no son protestas de sectores populares solamente, sino nuevos comportamientos colectivos en interacción con medios masivos. Dar visibilidad a la protesta social a través de los medios es una estrategia de legitimación y de consecución de las metas que plantean las organizaciones. En el caso de la tauromaquia, las posiciones a favor y en contra han llegado a los marcos interpretativos de los medios, con lo cual se ha logrado un cambio cultural que reconoce la importancia de los animales pero, al mismo tiempo, la protección de sus derechos. Los resultados del estudio muestran que, a medida que pasa el tiempo, se reduce la brecha tecnológica, es decir se incrementan las noticias en los cibermedios con origen en los movimientos sociales y particularmente en los movimientos animalistas. Estos últimos están conectados con los medios para dar visibilidad a sus intereses, sin embargo, ello no significa que los medios estén a favor de los movimientos pero sí de colocarlos a disposición de la opinión pública. En todo caso, los medios escritos han contribuido a un mayor entendimiento sobre la representación de movimientos animalistas colombianos.

Los derechos humanos han entrado en crisis en México. La libertad de expresión se ha vulnerado y los periodistas comprometidos con la construcción democrática se han convertido en objetivo de la criminalidad. La investigación no solamente pone su mirada en los periodistas, sino también en los criminales y en el papel del Estado. El derecho a la opinión y expresión, que fue materia de la Declaración de los Derechos del Hombre en Francia, se ha extendido por el mundo, especialmente en Occidente. El movimiento a favor de la democratización de los colectivos sociales y de las instituciones, entre ellas los Estados, ha estado acompañado recientemente de la violencia contra periodistas, que ha convertido al periodismo en una práctica riesgosa y carente de protección pública. México ha sido identificado con la prensa no libre porque no existen condiciones suficientes para el ejercicio de la libertad de prensa, como ocurre en Honduras, Ecuador, Venezuela y Cuba. México se ha caracterizado por una configuración monopólica desde la radio y la prensa hasta los nuevos canales y tecnologías que han llegado a la entrada del siglo XXI. Dicho país está por encima de este alcance en la concentración de propiedad de los medios en comparación con países desarrollados ya que la tendencia va de alta a muy alta. La concentración ha afectado las posibilidades de pluralismo y la libertad de expresión frente a la violación de los derechos humanos. Se requiere el desarrollo de diversas alternativas para producir solidaridad que haga visible el drama colectivo y la supremacía de los derechos humanos.

El libro contiene siete capítulos con siete temas específicos que están interconectados por diversos problemas en el contexto de las ciencias sociales actuales que han construido un pluralismo teórico, epistemológico y metodológico. Así mismo, reconoce el valor de la multiplicación de experiencias locales y particulares en diversos contextos geográficos, sociales y culturales. El libro sigue la propuesta de Ulrich Beck de superar el nacionalismo metodológico y acepta también la sugerencia de Immanuel Wallerstein de abrir las ciencias sociales. 
Milcíades Vizcaíno G.. Reseña sobre Ciudadanías conectadas. Sociedades en conflicto ...

\section{Notas}

* Reseña

Licencia Creative Commons CC BY 4.0

Cómo citar esta reseña: Vizcaíno G., M. (2019). Reseña sobre Ciudadanías conectadas. Sociedades en conflicto. Investigaciones sobre medios de comunicación, redes sociales y opinión pública, de Carlos Andrés Charry Joya. Universitas Humanistica, 88. https://doi.org/10.11144/Javeriana.uh88.rccs 